\title{
Article \\ The Parascientific Communication around Didier Raoult's Expertise and the Debates in the Media and on Digital Social Networks during the COVID-19 Crisis in France
}

\author{
Julien Longhi 1
}

AGORA Lab, IDHN, IUF, CY Cergy Paris Université, F-95000 Cergy-Pontoise, France; Julien.Longhi@cyu.fr

\begin{abstract}
Didier Raoult has acquired media authority in the debates on the treatment of COVID-19 in France thanks to his professional competence, raising issues of legitimacy and authority. He presents himself as a "star of infectious diseases", belonging to the "elite". In the press and online comments, the scientificity of the subject is mixed with considerations that may seem trivial. This paper will analyze the way in which scientificity is expressed in the media coverage of the scientist but also the way in which online communities discuss, argue, and become involved in polemics and controversies concerning him. It will analyze the links and shifts between scientific and parascientific communication. It will, therefore, deal with both the discourse and the staging around the scientist Didier Raoult and the circulation of his words and positions through online media and citizen communities.
\end{abstract}

Keywords: discourse analysis; digital humanities; textometry; authority; legitimacy

\section{Introduction}

Didier Raoult has acquired media authority in the debates on the treatment of COVID19 in France thanks to his professional competence, raising issues of legitimacy and authority. He presents himself as a "star of infectious diseases" (see, for example, Le Soir, 2 June 2020), belonging to the "elite". Several long interviews have given Didier Raoult a platform since March 2020 and, in particular, during the period of lockdown in France. In one of them (LCI, 27 May 2020), for example, Didier Raoult is presented as an "iconoclast virologist from Marseille", which already indicates the areas which this interview fits into: personality ("iconoclast"), profession ("virologist"), and geographical origin ("from Marseille"). The scientificity of the subject is mixed with considerations that may seem trivial which will be of interest in this article. This paper will analyze the way in which scientificity is expressed in the media coverage of the scientist but also the way in which online communities discuss, argue, and become involved in polemics and controversies. Noting that scientific disagreements quickly turn, in the public space and sometimes in the media, into polemics and conflicts, we will try to observe the links and shifts between scientific and parascientific communication and examine the boundaries between scientific, parascientific, and activist communication. This paper will, therefore, deal with both the discourse and the staging around the scientist Didier Raoult and the circulation of his words and positions through online media and citizen communities.

\section{Materials and Methods}

As the objective of this article is to analyze the discourse of a controversial scientist and the media, social reactions, and parascientific discourses around these controversies, I gathered a heterogeneous corpus [1] composed of documents of two genres revolving around a "discursive moment". For [2], "insofar as the aim is to follow current events at the moment of their actualization, this involves resorting to successive "small corpora", even when dealing with a long-term event. This leads us to compare the history of this 
pandemic between different countries and different "discursive moments" and to examine the way in which the "information narratives" of the written press work."

Bearing this in mind, I focused on a specific discursive moment (the first week of June 2020) in two specific actualization contexts: the press and social networks (Twitter). This period corresponds to a moment of controversy, as two scientific studies-one published in the scientific journal The Lancet, the other called "Recovery" - reached opposite conclusions on the use of hydroxychloroquine, followed by a retraction from the researchers behind The Lancet article in favor of using the drug.

These two publications are:

(1) Mehra, M. R., Ruschitzka, F., \& Patel, A. N. (2020). Retraction-Hydroxychloroquine or chloroquine with or without a macrolide for treatment of COVID-19: a multinational registry analysis. The Lancet, 395(10240), 1820.

(2) Horby, P., \& Landray, M. Low-cost dexamethasone reduces death by up to one-third in hospitalized patients with severe respiratory complications of COVID-19 [Internet]. RECOVERY Trial, 2020.

This very complex scientific subject (efficacy of a treatment, test protocols, validation of scientific trials) is thus discussed in the media and social media, producing reactions, comments, and, indeed, judgements without the protagonists necessarily having all of the elements or the necessary skills to form a judgment. In the French context, these publications had a very strong echo due to their media coverage, since Professor Didier Raoult, a French microbiologist specializing in infectious diseases and, at the time, director of the IHU in Marseille, received a lot of media attention for his very confident statements on the effectiveness of this treatment. This gave rise to many discussions and controversies, particularly during the periods of lockdown, which gave these debates a very large scope and resonance. The two "small" corpora under study are presented in Table 1:

Table 1. Description of the two corpora.

\begin{tabular}{cc}
\hline Press corpus & Social media: comments on an interview by Raoult \\
\hline $\begin{array}{c}\text { Articles published between 1 June and 7 } \\
\text { June on Factiva (excluding Agence France } \\
\begin{array}{c}\text { Presse) on the keywords "Didier" }+ \\
\text { "Raoult", a total of 89 pieces }\end{array}\end{array}$ & $\begin{array}{c}\text { with Ruth Elkrief and Margaux de Frouville on } \\
\text { 3 June 2020 } \\
\text { keywords "raoult" + "bfm" and the replies to } \\
\text { these Tweets) }\end{array}$ \\
\hline
\end{tabular}

The advantage of working on a "small corpus" is explained in [3]: a small corpus makes it possible to "identify language forms that are not necessarily "frequent", in the statistical sense of the term, but "emergent" forms which reflect the present time"; and this corpus "makes it possible to "set a date" in history". On the more precise choice of these two types of data, I refer to works that deal with press and tweet corpora in order to take into account precisely the stakes of these two kinds of discourse and of the devices in which they are integrated.

With regards to the press, ref. [2] has shown that "the observation of corpora collected over successive "moments discursifs" of the COVID-19 pandemic in the French media ... leads us to question the "meaning" that the discourse gives to words and figures in their quotations and contexts in the course of the news, as well as the "social meaning" that the media discourse builds around this pandemic". For the author, the form and meaning of information narratives are important in understanding "the reconfiguration of the theme of confidence" (for example, "discussion of state and institutional policies, distrust or mistrust of ordinary citizens but also of the traditional political parties").

With regards to social media, ref. [4] shows that "exploring the topics of discussion on Twitter and understanding which ones are controversial is extremely useful for a variety of purposes, such as for journalists to understand what issues divide the public or 
for social scientists to understand how controversy is manifested in social interactions". From a methodological point of view, works such as [5] have shown the advantage of a "method combining large-scale network and lexicometric analysis to link identifiable communities of Twitter users with the main discursive themes", and this analysis confirms that "political engagement and cultural dispositions are keys to understand[ing] different attitudes on Twitter".

To analyze this corpus, I combined two approaches (methods) whose theoretical linking I presented in [6]: discourse analysis and digital humanities.

Concerning discourse analysis, generally speaking, "the common ground of discourse researchers is that they understand discourse as a complex object that can be studied from various angles" [7] (p. 6). Discourse analysis is based, in particular, on a critical tradition stemming from the analysis of discourse à la française as defined by [8] (p. 14): "[f]rom 1969 onward, Foucault discovered that discourse is about more than isolated abstract signs. If discursive activity is now conceived of as the creation of networks or discursive formations of utterances, it is this theoretical shift towards the problem of the enunciation that has made the analysis of discourse possible." Thus, the corpora that we will look at in order to grasp the subject at hand will have to be analyzed both linguistically and semantically but also contextually and ideologically, which will influence the method of analysis used. To go further and clarify my position, I quote [7] (pp. 2-3): "Discourse Studies is an extremely heterogeneous field involving scholars from a range of disciplines"; and "Discourse Studies does not consider meaning as a given which can be read off the textual surface and reconstructed in spontaneous acts of understanding ... discourse analysts study the way the social order is constructed in discursive practice"; they are interested "in the practices, rules, or mechanisms that can explain how meaning is negotiated between the members of a discourse community". It will, thus, be necessary to contextualize the meanings observed in the corpus and to analyze not only the manifestations of meaning but also the mechanisms of its construction. That is why I used digital humanities and, more precisely, textometry. To summarize my previous work, I refer to [9]: textometry, a branch of textual statistics, offers an instrumented approach to corpus analysis, joining up quantitative syntheses and analyses of text [10]. Functionally, textometry implements differential principles. This approach highlights similarities and differences observed in the corpus according to the representation dimensions considered (lexical, grammatical, phonetic, prosodic, etc.) and establishes contextual and contrastive modeling. It is, therefore, well suited to the challenges of discourse analysis that I have highlighted. For this paper, I used the Iramuteq software, which offers a set of analysis procedures for the description of a textual corpus (Iramuteq is downloadable at http:/ / www.iramuteq.org, (accessed on 20 January 2022) and comes with extensive documentation and case studies. More precisely, Iramuteq is an interface for $\mathrm{R}$, which can be used to make multidimensional analyses of texts and questionnaires). One of its principal methods is Alceste. This allows a user to segment a corpus into "context units", to make comparisons and groupings of the segmented corpus according to the lexemes contained within it, and then to seek "stable distributions" [11]. These groups are represented using hierarchical descending classifications (HDC). This method allows users to map out the dynamics of the discourses of the different subjects engaged in interaction [12]. The vocabulary of the corpus is "used to build a doubleentry table listing the presence/absence of the full forms selected in/from the segments; a series of bi-partitions are [then] performed on this table based on a factorial analysis of correspondences". This construction establishes relations with three types of entities [11]: "(a) the terms (in columns); (b) the propositions (in rows); (c) the corpus (the table)", which joins the three levels of analysis "also evoked by Peirce in his triadic division of the 'symbols' (i.e., the conventional 'signs' of which the language productions are a part)", namely, the "terms", the "propositions", and the "arguments". Finally, this model aims at "mapping" the main topical foundations, or "topoi", on which this world of discourse is constructed by enunciators. 
These classifications allow us to understand the themes of a corpus through the lexical worlds that compose them.

Before starting to analyze the corpora, it is necessary to consider the relationship between communication and science. According to [13], publications "which we call 'parascientific' are distinctive in that they seek to communicate to an audience both within and outside the formal scientific community". They quote the anthropologist George Marcus who used the prefix "para" to highlight "how ambiguously alternative perspectives emerge amid moderately empowered people involved explicitly with major institutional powers" [14] (p. 5). For them, this prefix "locates parascientific publications alongside peer-reviewed scientific journals", and they identify "parascientific media as an influential genre" in order to "explore the epistemic cultures of those who are neither acknowledged experts nor disempowered actors" (reporters, editors, and board members of parascientific media). In terms of discourse analysis, this is very interesting, as it relates both to questions of authority/legitimacy (which may refer more to questions of enunciation, ethos) and to questions of discourse genres and their textual norms. Their work is, thus, original, because they focus on "how certain forms of media deliberately intervene in technical knowledge as it travels beyond its supposed site of production", thus taking a different view from that according to which science and the media are two distinct institutions; the authors point out that "because these publications are designed to orient attention to their content rather than their editorial processes, their role as agents in actively coordinating those exchanges, and not just as arenas in which they take place, is often rendered invisible". To complete this, and to go more specifically to the context which interests us, it is also worth taking into account the work of [15], which shows that, regardless of the challenge to the notion of linear scientific progress, there is no doubt that scientific knowledge is growing fast; however, whilst "the process of accumulation taking place in scientific disciplines is widely studied ... the way in which information accumulates and knowledge grows in nonscientific areas is less known". In her book Science Communication Online: Engaging Experts and Publics on the Internet, [16] looks "specifically to microblogs, Wikipedia, and an online database of radiation contamination readings as emerging forms of science communication online". She expands the work of [13] by putting forward the notion of "parascientific genres". For her, "the importance of a conversational model of science communication should not be underestimated."

Among the genres that contribute to the dissemination of scientific information without falling directly under the scientific category, journalistic discourse is a good example, especially in contexts such as health crises that generate a large amount of information. According to [17], journalistic discourse has two aims:

- $\quad$ "an ethical aim to transmit information in the name of democratic values: citizens need to be informed so that they can take part in public life";

- $\quad$ and a commercial aim to attract the largest possible number of readers, listeners, and viewers.

According to him, this gives rise to two issues at stake: "credibility" (treat information "in the most credible way possible") and "capture" ("treat information in such a way as to capture the largest possible number of receivers"). We can thus see how, in science, these two issues can sometimes clash and provoke complex reactions online. Furthermore, on the subject of scientificity, ref. [16] notes that "parascientific genres ... borrow scientific authority and knowledge structures from the realm of science, but they operate outside the conventional models of gatekeeping and reporting found in internal science communication". Thus, despite its declared ethical aim, press discourse cannot guarantee the same scientific validity as the scientific genres themselves; this can create gaps in information but also in reception, since not all readers have the scientific knowledge required to understand the issues covered by an article: "parascientific genres borrow some features from the internal discourse of science without the whole complex of features upon which the epistemic authority of science depends" [16]. The controversies on social networks also support the idea that there is a scientific ideology, as described by [18] when discussing an open letter 
published in the French newspaper Le Figaro and signed by 40 prominent scientists. This letter, they state, is an example of scientific ideology, which also displays some propaganda features: "some of the elements of scientism and propaganda are used in order to support a political conception of institutional science as the only serious source of knowledge."

\section{Results}

In this section, I will present the successive analyses of the two subcorpora using the method described in Section 2 above. In particular, I will detail the lexical classes by providing representative examples. Drawing on these two analyses, I will then be able to examine issues pertaining to the parascientific communication around the figure of Prof. Raoult in the discursive moment chosen.

\subsection{Media Articles about Didier Raoult}

Using the Iramuteq software, I applied the Alceste method-presented in Section 2and obtained the dendrogram presented in Figure 1:

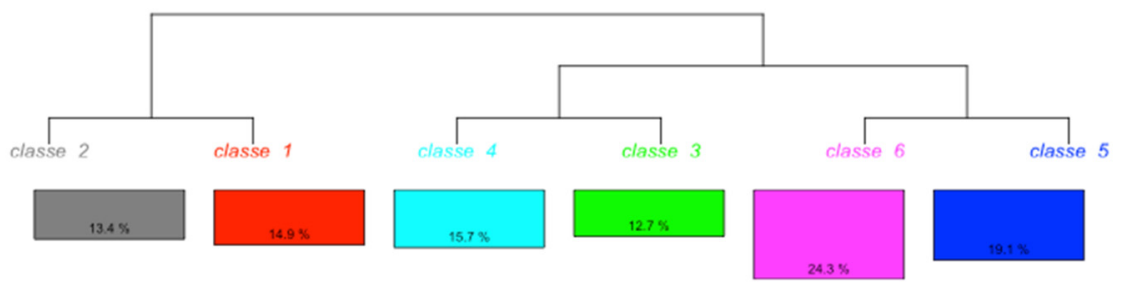

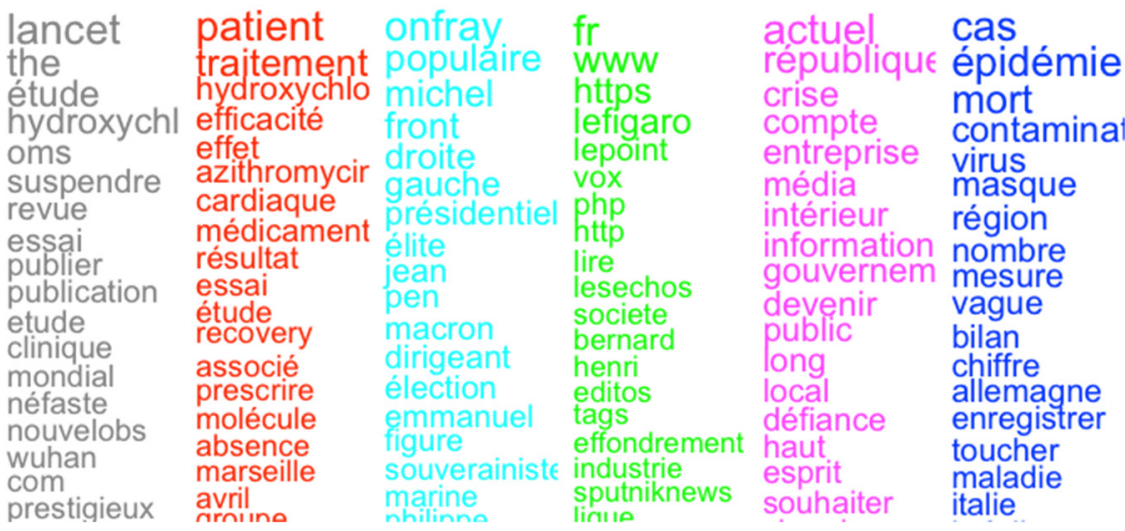

Figure 1. HDC of the press corpus.

These classes were, therefore, derived from a statistical classification which brought together terms that were close to each other. Looking closely at the terms grouped in the various classes and reading the text segments that led to these groupings, we chose to focus on three particular classes (which correspond to clusters of terms that refer to actual topics, rather than communicational or contextual aspects):

- $\quad$ Class 1 (14.9\% of text segments), which contains texts about the efficacy, effects, and results of hydroxychloroquine, the drug advocated by Prof. Raoult;

- Class 2 (13.4\% of text segments), which discusses the scientific validation (in journals such as The Lancet) of the study and whether or not the drug should be authorized for treating patients;

- $\quad$ Class 5 (19.1\% of text segments), which deals with the epidemic and numbers (using words like "cases", "deaths", etc.).

Looking at these three classes will help us to see the way in which Prof. Raoult and his work have been presented in the press.

In the Iramuteq program, it is possible to select "characteristic text segments" which are the most representative of a given class (as they contain the most words belonging to that class). In the case of Class 1, three examples are good illustrations of what the press has 
to say about the subject (the analyses were done on the French corpus, but the examples are translated into English):

(1) Chloroquine mega-study impossible to verify after all. Hydroxychloroquine has "no beneficial effect" in COVID-19 patients according to British Recovery Trial leaders, who yesterday announced an "immediate" halt to the enrolment of new patients for this treatment. The first major clinical trial to produce results, it was one of the few not to suspend hydroxychloroquine tests in the wake of the study in The Lancet. The trial is controlled and randomized (patients are selected by drawing lots), which is considered the most robust method. It has been conducted in the UK on over 11,000 patients from 175 hospitals in order to assess the efficacy of several COVID-19 treatments. Tests on options other than hydroxychloroquine continue. (Var Matin, 6 June 2020)

In this section, we note the use of quotation marks to present the point of view of scientists whose conclusions contradict those of Prof. Raoult. This distancing is also supported by the phrase "considered the most robust method", which endorses, and gives credibility to, the information conveyed by the article. Another article chooses to detail the conditions in which the study published in The Lancet was conducted and questions its veracity (and, therefore, the arguments against the efficacy of hydroxychloroquine):

(2) The findings of the study published in The Lancet cover a total of 96,000 patients, all infected with COVID-19, who were admitted to 671 hospitals on six continents between 20 December 2019 and 14 April 2020. Of these, 15,000 patients split into four groups were treated with the drug, either alone or in combination with others. The results of the study on the non-efficacy of hydroxychloroquine in the treatment of COVID-19 as recommended by Prof. Didier Raoult, published by the prestigious British scientific journal The Lancet, have had a worldwide political and health impact. (El Watan, 6 June 2020)

The article highlights the prestigious nature of the journal and seems to emphasize the method (using a series of figures), which gives credence to the opposition to the treatment advocated by Prof. Raoult. This methodological argument is further detailed in the following excerpt, which clarifies the concept of evidence-based medicine (EBM):

(3) The controversy over the benefits of chloroquine or, more precisely, hydrochloroquine in the treatment of COVID-19 concerns the experience of Professor Didier Raoult of the Hôpital de la Timone Laboratory in Marseille. According to his results, hydrochloroquine, combined with azithromycin, apparently has a positive effect in COVID-19 patients. ... Criticism of this approach, both by French doctors and by national societies in other countries and international medical societies, relates to the study design used by Prof. Raoult, which does not follow the rules of "evidence-based medicine" (EBM). In the series treated in these experiments, there was no control group and no randomization of patients, on the grounds that this was an emergency treatment in the absence of other therapeutic alternatives. Furthermore, the criteria for including patients were not clearly defined. The results obtained cannot, therefore, be reliable according to EBM. Above all, they have never clearly demonstrated that there is a significant reduction in mortality. The reduction in the viral load and the improvement in symptoms detected in Prof. Raoult's experiment are not enough to affirm the efficacy of this therapeutic regimen. (Libération, 2 June 2020)

The use of the adverb "apparently" at the beginning of the paragraph casts doubt on the beneficial effects of this drug, and what follows makes this explicit: "does not follow the rules", "cannot, therefore, be reliable", "are not enough to affirm".

In the case of Class 2, the articles again tell the story of this controversy, but they also include the news that trials of this drug have been resumed, thus offering a more positive overall view of Prof. Raoult's treatment: 
(4) Published on 22 May, this study-which came after several others in the same veinhad concluded that hydroxychloroquine was not beneficial for hospitalized patients and could even have a significant harmful effect (see our 24 May issue). Its publication had caused a global stir and had spectacular repercussions, such as prompting the WHO to suspend clinical trials for this treatment. But in the end, after much criticism of the study's methodology, including from scientists who were skeptical about the benefits of hydroxychloroquine, the WHO announced on Wednesday that it would resume clinical trials of this drug. (Var Matin, 6 June 2020)

The narrative is well constructed, using several tenses and a "punchline" that is intended to be favorable, whilst relegating to the background (between hyphens) elements that are rather unfavorable ("which came after several others in the same vein"). This is perceptible in example 5, which also uses several tenses:

(5) During a video conference, the WHO Director said: “On 25 May, the global health authority had announced the suspension of hydroxychloroquine trials following the publication of a study in the medical journal The Lancet which found the use of chloroquine or its derivatives, such as hydroxychloroquine, against COVID-19 to be ineffective and even harmful." He added: "The suspension of the trials was to allow the WHO to analyze the information available, and a decision was expected by mid-June." In the end, the decision came sooner than expected, since, at Wednesday's press conference, the WHO announced that the trials would resume. "We are now fairly confident that we have not seen any differences in mortality," Soumya Swaminathan, the WHO's Chief Scientist, told a news videoconference held at the organization's headquarters in Geneva on Wednesday.

(El Watan, 6 June 2020)

Thus, Classes 1 and 5 discuss the validity of hydroxychloroquine, with a negative focus (The Lancet study) or a positive one (WHO recommendations), which shows the polarization of the debate.

Text segments in Class 5 are more factual, containing lots of figures (example 6), developments/trends (examples 6 and 7), or conclusions about the figures:

(6) Yesterday, Brazil passed the milestone of 30,000 deaths due to the coronavirus, but the country's sharp rise in the number of cases has not deterred Rio de Janeiro or Sao Paulo from beginning to come out of lockdown. The country suffered another 1262 deaths, the worst daily toll since 21 May (1188), the health ministry said. Brazil, a country of 212 million people which accounts for more than half of coronavirus infections and deaths in Latin America, has recorded 555,383 confirmed COVID-19 cases, following yet another sharp rise of almost 29,000 infections in $24 \mathrm{~h}$. These figures, which the scientific community believe to be grossly underestimated, place Brazil fourth in the world in terms of deaths, behind the US, UK, and Italy. (Sciencesetavenir.fr, 3 June 2020)

(7) With the decrease in the number of confirmed cases and the number of deaths varying between 6 and 8 compared to the beginning of the pandemic, some wilayahs are seeing large numbers of cases compared to other regions in the country. (El Watan, 6 June 2020)

(8) These are targeted surveys to monitor new cases in these areas and break the chain of infection. Epidemiology teams are already on the ground to identify all these cases, which generally occur as a result of easing precautionary measures and in particular failing to observe physical distancing. (El Watan, 6 June 2020)

We can thus conclude that the press presents the controversy surrounding Prof. Raoult by providing a chronological account of his medical recommendations, which it integrates into a fairly slanted narrative, even if certain parts of the articles are more factual. It also stages the controversy between several studies, focusing on either the questioning of The Lancet study or the WHO's validation of the trials.

In order to study the way in which these press discourses are disseminated, I propose to now look at reactions on Twitter to a specific interview with Prof. Raoult and, thus, to gauge the particularity of this type of communication. 


\subsection{Twitter Comments on Didier Raoult's Interviews}

The following explanation by [16] touches on the importance of turning our attention to this corpus: "[t]hese forms of online science communication offer valuable insights for rhetorical scholars interested in how genres of communication evolve and change." Indeed, we need to take into account "the complexities between highly codified spheres of discourse, rapidly evolving public discourse, and the intersection of media change". In order to follow and apply this suggestion, I propose a linguistic study of 604 Tweets written about a BFM TV interview given to Ruth Elkrief and Margaux de Frouville on 3 June 2020 (presented in Figure 2). BFM is a 24-h news channel which has given a lot of media coverage to the pandemic and has also contributed to the appearance of medical experts on television. It is, therefore, a good illustration of the importation of scientific discourse into the media sphere-and the problems that this can pose-in the context of an interview on a very specific subject aimed at the general public.

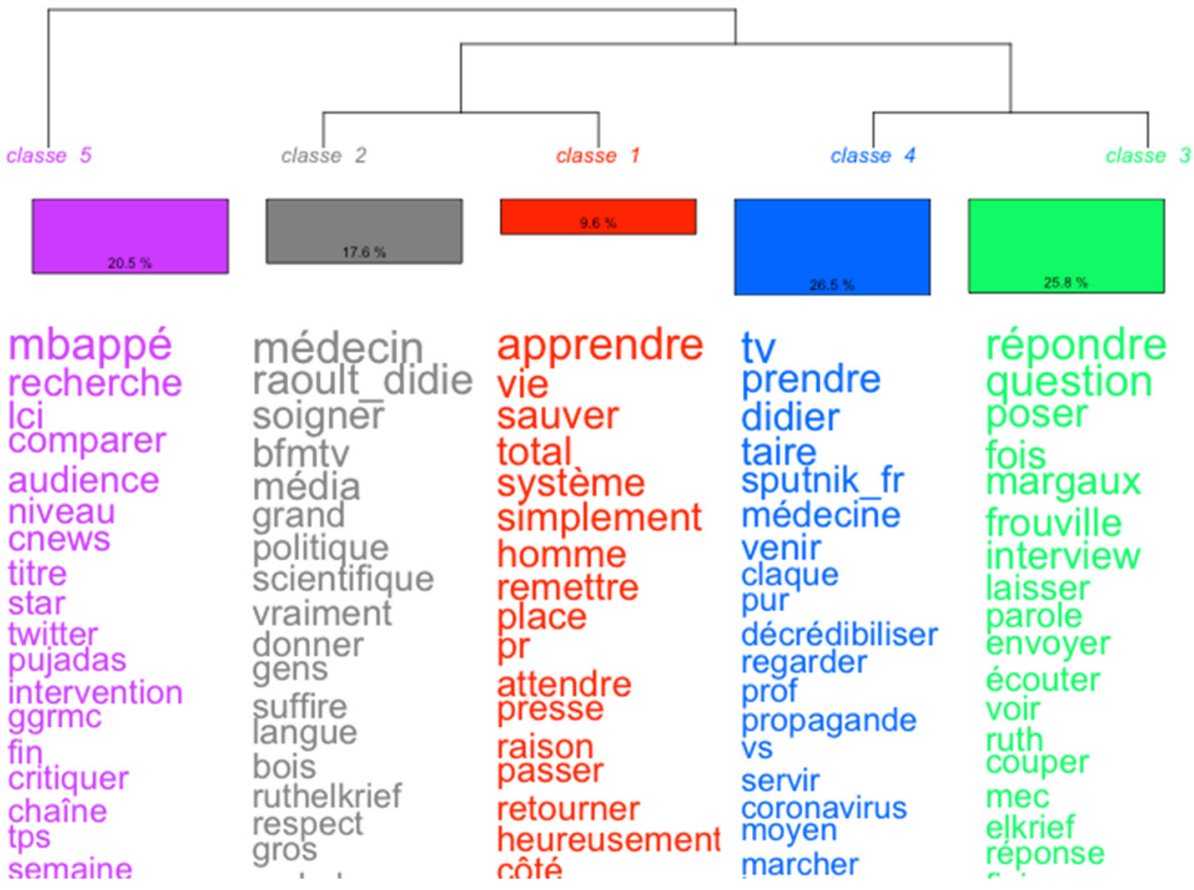

Figure 2. HDC of the corpus of Tweets.

This classification highlights messages that can be grouped based on the following themes:

- $\quad$ Class 5: the comparison with the footballer Mbappé and its consequences;

- Classes 3 and 4: conflicts sparked by the interview, whether with the journalists or, by extension, with the media in general;

- Classes 1 and 2: appreciation for Professor Raoult or discussion of his competence.

Taking a closer look now at the corpus, we can see how commenters give accounts of a long interview bearing on the scientific dimension of the controversy. Twenty per cent of the comments deal with Didier Raoult's status as a "star" (Class 5) in relation to the comparison with the footballer Mbappé:

(9) *****2020-06-03*tweet 263

Maybe one day BFM will stop rolling out the red carpet for him ... ratings clearly take precedence over journalistic interest. And the headline "Didier Raoult, the mbappé of research?" is jarring.

(10) *****2020-06-03*tweet401

they said raoult is the mbappé of research hahaha bfm comes up with the best headlines 


\section{(11) *****2020-06-04*tweet18}

No it's not true what he says! "mbappé of research" was used by BFM. Raoult said you are not going to compare mbappé with a 3rd division goalkeeper. He particularly wanted to emphasize the ignorance of scientists, researchers in France drawing a comparison with footballers

These three examples deal with BFM TV's headline about this comparison, the legitimacy of this comparison, and the role of the media ("rolling out the red carpet", "ratings clearly take precedence over journalistic interest"). Indeed, in an attempt to point out the public's lack of understanding of the level and hierarchy of scientists, Prof. Raoult compared himself to the prestigious footballer Killian Mbappé, drawing an analogy with him in the field of research. These few examples show the polemical dimension found on social networks whenever he gives an interview. The social dimension becomes an element that needs to be taken into account when considering authority and legitimacy in digital spaces, since, although he is very well known institutionally, the "star status" which he has been staging seems to be subject to controversy or comments.

Twitterers' reactions help convey, consolidate, or challenge the legitimacy and/or authority of public figures during their media appearances. In Didier Raoult's case, some of the messages relate to a conflictual representation of the situation.

We can see that Classes 3 and 4, accounting for around $50 \%$ of the comments, focus on the conflict. Class 4 (a quarter of the text segments) includes messages from the @spoutnik_fr account about the heated exchange between Didier Raoult and Margaux de Frouville. Thus, all messages share a similar form.

(12) **** 2020-06-04*tweet91

"Shush, be quiet!": Didier Raoult lashes out at a BFM TV journalist: via @sputnik_fr

Here, "via@sputnik_fr" means that the @sputnik_fr account has retweeted messages posted by various Twitterers reacting to the same incident. According to the Wikipedia page on this media outlet, "Sputnik ( . . f formerly Voice of Russia and RIA Novosti ... ) is a Russian state-owned news agency, news website platform, and radio broadcast service. It was established by the Russian government-owned news agency Rossiya Segodnya on 10 November 2014. ... Sputnik is frequently described as a Russian propaganda outlet. ... Sputnik operates news websites, featuring reporting and commentary, in 31 languages, including English, Spanish, Polish, and Serbian." These contextual elements are useful in terms of taking into consideration the socio-political aspects of the discourse and the enunciative anchoring; indeed, discourse analysis is interested in the points of view of the enunciators and takes into account the places occupied in the social space, particularly the media. Thus, these Tweets record the "clash" that occurred when Didier Raoult asked one of the interviewers to be quiet while he answered.

Several other examples relate the same episode but comment on it positively, siding with Prof. Raoult:

(13) ****2020-06-04*tweet35

Be quiet! Raoult vs Elkrief on BFM! Brilliant interview! via@YouTube

(14) ****2020-06-04*tweet32

When \#Raoult tells the BMF journalist, "Be quiet!", he reminds us of 1 obvious fact: a professor of medicine speaking about his field is superior to a journalist. This is difficult to understand in an age of fanatical intellectual egalitarianism. But there it is.

(15) *****2020-06-04*tweet87

We may be shocked by a "shush, be quiet" (Raoult to @mdefrouville) but let's not forget that the daily symbolic violence perpetrated by the clique of BFM editorialists is infinitely more harmful than such indelicacy

In (13), the interview is appreciated for being hard-hitting; in (14) the user recognizes the professor's superiority; and in (15) the verbal violence is excused by pointing to the 
symbolic violence perpetrated by the media. Class 3, which is close to Class 4 discussed above, also deals with the interactions between the scientist and the journalists, this time pointing out either the latter's strategies for asking questions or their behavior during answers:

(16) *****2020-06-04*tweet126

@LeMediaTV I must be dreaming. Watching 2 BFM journalists interviewing Raoult and trying all along to trap him. Their technique: ask a question and not let him answer it so as to confuse the audience. Is this what we call journalists?

(17) ****2020-06-03*tweet350

Long live Professor Raoult long live Marseille we have the best professor these BFM $T V$ journalists are seriously starting to get on my nerves frankly they are really shit journalists and I support Didier Raoult he is a good man long live Marseille long live Didier Raoult

(18) ****2020-06-03*tweet 425

The live interview on BFM with Professor Didier Raoult is irritating, when he starts to answer their questions they immediately cut him off, whenever he tells them "I am speaking don't interrupt me" they dare say "it's an interview", bitches

The Tweets in this class sometimes display a degree of verbal violence (insults and abuses such as "shit journalists" in (17) and "bitches" in (18)). The virologist is also defended in other messages which legitimize him in different ways. Thus, the messages in Classes 1 and 2, which represent just over a quarter of the corpus, highlight either his pragmatism ("meanwhile he is saving lives") or his opposition to the system. They record the exchanges about the medical field and treatments; these messages particularly emphasize his supposed "anti-system" trait and his personality.

In Class 1, we find Tweets such as:

(19) $* * * * 2020-06-03 *$ tweet 271

He is right, since the beginning of the epidemic the government and BFM have discredited him, taken him for a charlatan, what do they do while he saves lives? Full support for $\mathrm{Mr}$ @raoult_didier people don't like to hear the truth, I hope he will be able to prove he was right

(20) ****2020-06-04*tweet152

it's the \#BFM journalists who stink. \#Raoult saves lives, is internationally recognized and these attack dogs treat him like a clown, ask him questions and ignore his answers. That's how they behave with anyone who is not in their ultraliberal camp

(21) *****2020-06-04*tweet148

No, it's logical that his supporters are enjoying this: he's doing exactly what they expect of him, he's the man who will have "put big pharma in place together with the JudeoIslamic-Bobo-Illuminati journos under Macron's heel" and "who says out loud what we actually think of BFM WC".

Twitterers show their support by using words such as "support" (example 19), "is internationally recognised" (20), and "the man who will have put big pharma in place" (21). However, whilst voicing their endorsement on the medical side of things, they also bring up politics ("ultraliberal camp" in (20)) and even conspiracy theories ("the Judeo-IslamicBobo-Illuminati journos under Macron's heel" in (21)).

Other messages focus on his legitimacy, especially in relation to the interviewers: over $17 \%$ of messages (Class 2) concern the professor's credibility (mainly good, sometimes bad) and the appropriateness (or not) of giving him a media platform. Here are a few examples of positive views: 
(22) *****2020-06-03*tweet 495

The guy is a professor of infectious diseases and Ruth Elkrief is giving him lessons in medicine ... sure. \#BFM \#Raoult

(23) *****2020-06-04*tweet83

Yes, be quiet you sh*t hack who wants to teach the great @raoult_didier about science... BFM really makes you want to puke..!!!

These examples show that he is seen as legitimate and should not be contradicted by a journalist (who is pejoratively called a "hack"). The term "lessons" indicates that his position is that of a master, despite his being contradicted. More broadly, though, we see from the tone of these messages that disagreements about science quickly turn into polemics and conflicts.

\section{Discussion}

The two corpora compiled around a specific discursive moment show that there is variety between media communication and communication on social networks; of course, this "gap" between two discursive practices is understandable, but, "content" gaps aside, it is the communicational gaps that are of more interest in this article. Indeed, within each of these genres we see divergences, in terms of what is said about the information, but also the forms that discourses can take, which raises questions about the very principles of parascientific communication.

By comparing discussion genres in relation to Prof. Raoult-the press and Twitter comments-we have identified salient features of each of these genres as well as discursive, communication, and argumentative differences. The controversy in the press surrounding Prof. Raoult provides a narrative that presents the specialist in a relatively axiologized way (positively or negatively); on Twitter, users point to disagreements about science, and discussions quickly turn into polemics and conflicts. We have also noted markers of reported discourse (quotation marks), qualifications (the journalist's point of view), and the use of arguments of authority (prestige of publishers, figures), highlighting the sometimes paradoxical dimension of the press, which is attached to factuality but presents points of view according to certain conclusions or editorial orientations.

This corpus study is, therefore, important because it shows that:

- the press genre, despite the injunction to inform readers, also has certain leanings, which are evident not so much in the content as in the narratives provided to readers: what are the "ingredients" of the story, how is it staged?;

- $\quad$ social networks are often blamed for spreading misinformation $([19,20])$ : for example, the report in [21] on "12 announcements by Facebook and five by Twitter aimed at reducing the circulation of misinformation on their platforms" between the 2016 election and 2019. In the present case, we sense a degree of violence towards the journalistic genre and, therefore, a conflict between the spheres of disseminating and constructing scientific knowledge; and, particularly in the context of scientific communication about health, we observe a polarization of points of view and also a transposition of the criteria of scientific authority (Prof. Raoult comparing himself to Mbappé, Tweets comparing the skills of the professor and journalists) and their impact (political dimension, questioning the media);

- information and opinion sometimes tend to be confused, and the instantaneousness of social networks should also be taken into account. That is why we have to consider the specific features of these kinds of discourse as well as the object of the polemics contained in them.

All of this argues for the need for a discursive consideration of parascientific genres; the previous points have highlighted the formal heterogeneity of the discourse genres considered, both internally (within each genre) and comparatively. However, given the differences in scientific knowledge and the porosity between scientific/media/social genres, we end up losing track of the source discourses and pass from information to polemics. We 
have seen that certain enunciative markers in the press (inverted commas, modals) already blur the transmission of information by integrating a certain point of view; this blurring becomes more pronounced on social networks, even going so far as to become sedimented when the debates are extremely polarized. For example, on Twitter, quotes are more about "punchlines", particularly offensive discursive sequences, than the reported presentation of factual elements.

Thus, parascientific communication can become activist communication. We have seen that, in the corpus of Tweets, some users mix political/conspiratorial considerations with statements about scientific credibility. To broaden the conclusions drawn about social media and their polemical dimension, I collected the Tweets (2177 as of 17 August) that used the hashtag \#noussavons ("we know"), which is used by antivaccine users in general but is especially anchored in conspiracy theories (they are hiding this or that truth, but "we know"). I will not go into the subject of conspiracy theories, false information, etc., but I am interested here in looking at the form that these messages take. Indeed, they are very different from the messages in the corpus discussed in 3.2. Appendix A lists 35 of the 37 most frequent active forms in this corpus; we can see that these are hashtags most of which combine several words, being similar to small phrases or formulas.

Some of these hashtags reflect the number of people who identify with \#noussavons and are linked to the various rallies that have taken place (including on 14 August, which is mentioned):

(24) \#noussommesdesmillions ("we are millions")

(25) \#noussommeslenombre ("we are many")

(26) \#noussommesdesmilliards ("we are billions")

The examples above use the structure "we + are + indication of a great number". In this respect, example 27 also bears similarities:

(27) \#tousunis ("all united")

A number of other messages have the form "no + preposition + noun + modifier" ("no + preposition + modifier + noun" in the English translation):

(28) \#nonaupassdelahonte ("no to shameful pass")

(29) \#nonalavaccinationobligatoire ("no to compulsory vaccination")

(30) \#nonaupassedelahonte ("no to shameful pass")

(31) \#nonaupasssanitaire ("no to health pass")

(32) \#nonauvaccinobligatoire ("no to compulsory vaccine")

Three relate to the health pass introduced in France in August 2021, which is either mentioned in a neutral way ("health pass" in (31)) or called "shameful" in (28) and (30) (there is some confusion about the French spelling of the word "pass"). Examples 29 and 32 refer to compulsory vaccines/vaccination (which is not the same as the health pass, since the latter can be obtained with a negative test or proof of having been infected with COVID-19).

Finally, there is a political side to a significant number of the hashtags used, as they express opposition to the French government's decision, having a very polarized dimension and denouncing the "dictatorial" way in which the health pass or vaccination has been implemented:

(33) \#boycottpasssanitaire ("boycott health pass")

(34) \#stopdictaturesanitaire ("stop health dictatorship")

(35) \#jenesuispasuncobaye (I am not a guinea pig")

(36) \#resistance

(37) \#gouvernementdelahonte ("shameful government") 
(38) \#vousserezjuges ("you will be judged")

With words like "boycott" (33), "dictatorship" (34), "guinea pig" (35), "resistance" (36), "government" (37), and "judged" (38), there is a clear move towards a politicized and even conspiratorial vision of the event, using hashtags that resemble political formulas or slogans.

Finally, there are two hashtags worth noting, as they follow an already much-used structure - "keep away from $\mathrm{X}^{\prime \prime}$ - which in this case relates to children/kids:

(39) \#touchepasamesenfants ("keep away from my children")

(40) \#touchepasamesgosses ("keep away from my kids")

Indeed, some of the objections raised concern the supposedly harmful nature of the vaccines for children.

Despite the diversity of these hashtags, it is notable that they are constitutive and representative of this new, highly polarized and politicized corpus. These results allow us, therefore, to point out an additional feature of parascientific communication on social networks: when it becomes radicalized, it is "condensed" into formulas or hashtags, which can be seen as signaling a move away from the scientific —and even parascientific-genre and towards propaganda discourse.

\section{Conclusions}

To conclude on the subject of the parascientific communication around Professor Raoult during a discursive moment of the COVID-19 health crisis, it appears that the attention given to a scientific debate by the press (efficacy of a treatment) or by social media (interview on the topic of health management) helps produce different narratives that present the events in different ways. In the absence of scientific points of reference, the press tries to report statements or developments, but it often takes an argumentative approach, which causes strong dissension and even controversy on social networks. This can lead-as in the political and polemical case of the health pass-to a blurring of the lines with the activist discourse. Generally speaking, this discursive moment reveals the whole complexity of parascientific communication, which diffusely mixes scientific, media, digital, citizen, and even activist types of discourse. This complexity is further exacerbated in the context of a health emergency such as the COVID-19 crisis and prompts us to take into account the various communication genres as necessary devices for transmitting and regulating information. Whilst a general scientific culture is, therefore, important to understand the issues at stake in a debate, a communication and discursive culture is also important in order to deal calmly with these discursive events and to take into account the otherness and diversity of points of view.

With regards to the question of knowing how parascientific communication differs from the scientific, our analysis shows the importance of taking account of the transposition from media to social media [22]: "individuals are turning to online platforms to learn about science and health topics, with the Internet dominating as the primary source of information about science and technology news." From these social media, new discourse practices are emerging, not only in response to boundary erosion in scientific communication [22] but also because of the polarization and controversies in which citizens are involved ([22] points out that " $37 \%$ of Facebook users regularly see news on Facebook about science and technology, and $46 \%$ see news about health and medicine").

With regards to the exploration of new, scientific or parascientific practices, and, in particular, digital communication, [23] shows (in relation to the COVID-19 epidemic) "the critical impact of this new information environment": "the information spreading can strongly influence people's behavior and alter the effectiveness of the countermeasures deployed by governments. In this respect, models to forecast "viral spread" are starting to account for the behavioral response of the population with respect to public health interventions and the communication dynamics behind content consumption." Thus, decoding 
and analyzing the media and social media, as well as working on media education and the exercise of critical thinking, is all the more necessary.

Funding: This research was funded by the Institut Universitaire de France (IUF), 2018 and the DIM (Domaine d'intérêt majeur) Sciences du texte et connaissances nouvelles, Région Ile de France.

Institutional Review Board Statement: Not applicable.

Informed Consent Statement: Not applicable.

Data Availability Statement: Not applicable.

Acknowledgments: I wish to thank Jeremy Demange, research engineer at IDHN, for extracting the Tweets used in this paper.

Conflicts of Interest: The author declares no conflict of interest.

\section{Appendix A}

List of the most frequent forms used in the corpus of Tweets based on the hashtag \#noussavons:

\begin{tabular}{|c|c|}
\hline \#noussavons ("we know") & 2177 \\
\hline \#noussommesdesmillions (“we are millions") & 653 \\
\hline \#nonaupassdelahonte ("no to shameful pass") & 615 \\
\hline \#manif14aout ("demonstration 14 August") & 335 \\
\hline \#nonalavaccinationobligatoire ("no to compulsory vaccination") & 263 \\
\hline \#tousunis ("all united") & 208 \\
\hline \#boycottpasssanitaire ("boycott health pass") & 198 \\
\hline \#nonaupassedelahonte ("no to shameful pass") & 171 \\
\hline \#passsanitaire (“health pass") & 163 \\
\hline \#bfmmenteurs (“lying BMF") & 146 \\
\hline \#mediasmenteurs ("lying media") & 143 \\
\hline \#ivermectinsaveslives & 141 \\
\hline \#jenesuispasuncobaye (I am not a guinea pig") & 140 \\
\hline \#trumprally & 139 \\
\hline \#thestormiscoming & 139 \\
\hline \#patriotes & 139 \\
\hline \#laissezlesmedecinssoigner ("let doctors treat [their patients]") & 139 \\
\hline \#godbless & 139 \\
\hline \#resistance & 134 \\
\hline \#nonaupasssanitaire ("no to health pass") & 134 \\
\hline \#manifs14aout ("demonstrations 14 August") & 129 \\
\hline \#noussommeslenombre ("we are many") & 120 \\
\hline \#nonauvaccinobligatoire ("no to compulsory vaccine") & 109 \\
\hline \#stopdictaturesanitaire ("stop health dictatorship") & 106 \\
\hline \#gouvernementdelahonte (“shameful government") & 100 \\
\hline \#vousserezjuges ("you will be judged") & 96 \\
\hline
\end{tabular}




\begin{tabular}{ll}
\hline \#passsanitairedelahonte ("shameful health pass") & 89 \\
\hline \#noussommesdesmilliards ("we are billions") & 87 \\
\hline \#stopaumassacre ("stop the massacre") & 80 \\
\hline \#touchepasamesenfants ("keep away from my children”) & 74 \\
\hline \#liberte ("freedom") & 69 \\
\hline \#covid & 61 \\
\hline \#va ("go") & 60 \\
\hline \#touchepasamesgosses ("keep away from my kids") & 60 \\
\hline \#manifestation14aout ("demonstration 14 August") & 60 \\
\hline \#passdelahonte ("shameful pass") & 57 \\
\hline
\end{tabular}

\section{References}

1. Garric, N.; Longhi, J. L'analyse de corpus face à l'hétérogénéité des données: D'une difficulté méthodologique à une nécessité épistémologique. Langages 2012, 3, 3-11. [CrossRef]

2. Moirand, S. Instants discursifs d'une pandémie sous l'angle des chiffres, des récits médiatiques et de la confiance. Repères Dorif 2021, 24. Available online: https:/ / www.dorif.it/reperes/sophie-moirand-instants-discursifs-dune-pandemie-sous-langle-deschiffres-des-recits-mediatiques-et-de-la-confiance/ (accessed on 10 October 2021).

3. Moirand, S. L'apport de petits corpus à la compréhension des faits d'actualité. Corpus 2018, 18. [CrossRef]

4. Garimella, K.; Mathioudakis, M.; Morales, G.D.F.; Gionis, A. Exploring controversy in twitter. In Proceedings of the 19th ACM Conference on Computer Supported Cooperative Work and Social Computing Companion, San Francisco, CA, USA, 27 February-2 March 2016; pp. 33-36.

5. Smyrnaios, N.; Ratinaud, P. The Charlie Hebdo attacks on Twitter: A comparative analysis of a political controversy in English and French. Soc. Media Soc. 2017, 3, 2056305117693647. [CrossRef]

6. Longhi, J. Proposals for a discourse analysis practice integrated into digital humanities: Theoretical issues, practical applications, and methodological consequences. Languages 2020, 5, 5. [CrossRef]

7. Angermuller, J.; Maingueneau, D.; Wodak, R. The Discourse Studies Reader: Main Currents in Theory and Analysis; John Benjamins Publishing Company: Amsterdam, The Netherlands; Philadelphia, PA, USA, 2014. [CrossRef]

8. Angermuller, J. Poststructuralist Discourse Analysis: Subjectivity in Enunciative Pragmatics; Palgrave Macmillan: Basingstoke, UK, 2014. [CrossRef]

9. Longhi, J.; Saigh, D. A textometrical analysis of french arts workers "fr. intermittents" on twitter. In Proceedings of the 4th conference CMC and Social Media Corpora for the Humanities, Ljubjana, Slovenia, 17-18 September 2018; Available online: https://nl.ijs.si/janes/wp-content/uploads/2016/09/A-Textometrical-Analysis-of-French-Arts-Workers-Intermittentson-Twitter.html (accessed on 10 September 2021).

10. Lebart, L.; Salem, A. Statistique Textuelle; Dunod: Paris, France, 1994.

11. Reinert, M. Quel objet pour une analyse statistique du discours? Quelques réflexions à propos de la réponse Alceste. In Proceedings of the JADT, Nice, France, 19-21 February 1998; Available online: https:/ /lexicometrica.univ-paris3.fr/jadt/jadt199 8/reinert.htm (accessed on 10 September 2021).

12. Reinert, M. Quelques interrogations à propos de l'"objet" d'une analyse de discours de type statistique et de la réponse" Alceste". Langage Société 1999, 90, 57-70. [CrossRef]

13. Kaplan, S.; Radin, J. Bounding an emerging technology: Para-scientific media and the Drexler-Smalley debate about nanotechnology. Soc. Stud. Sci. 2011, 41, 457-485. [CrossRef]

14. Marcus, G. Para-Sites: A Casebook Against Cynical Reason; University of Chicago: Chicago, IL, USA, 2011.

15. Petrovich, E. Accumulation of knowledge in para-scientific areas: The case of analytic philosophy. Scientometrics 2018, 116, 1123-1151. [CrossRef]

16. Mehlenbacher, A. Science Communication Online: Engaging Experts and Publics on the Internet; The Ohio State University Press: Colombus, OH, USA, 2019. [CrossRef]

17. Charaudeau, P. Discours journalistique et positionnements énonciatifs. Frontières et dérives. Semen. Revue de Sémio-Linguistique des Textes et Discours 2006, 22. [CrossRef]

18. Garric, N.; Goldberg, M. Mise en scène de la scientificité dans le débat citoyen. Le cas des OGM comme argument d'une lettre ouverte autour de la science. MEI-Médiation et Information 2012, 35, 161-171.

19. Wang, Y.; McKee, M.; Torbica, A.; Stuckler, D. Systematic literature review on the spread of health-related misinformation on social media. Soc. Sci. Med. 2019, 240, 112552. [CrossRef] [PubMed]

20. Longhi, J. Mapping information and identifying disinformation based on digital humanities methods: From accuracy to plasticity. Digit. Scholarsh. Humanit. 2021, 36, 980-998. [CrossRef] 
21. Allcott, H.; Gentzkow, M.; Yu, C. Trends in the diffusion of misinformation on social media. Res. Politics 2019, 6, 2053168019848554. [CrossRef]

22. Bode, L.; Vraga, E.K. See something, say something: Correction of global health misinformation on social media. Health Commun 2018, 33, 1131-1140. [CrossRef] [PubMed]

23. Cinelli, M.; Quattrociocchi, W.; Galeazzi, A.; Valensise, C.M.; Brugnoli, E.; Schmidt, A.L.; Zola, P.; Zollo, F.; Scala, A. The COVID-19 social media infodemic. Sci. Rep. 2020, 10, 16598. [CrossRef] 